\title{
SENSE OF COMMUNITY, PEER FEEDBACK AND COURSE ENGAGEMENT AS PREDICTORS OF LEARNING IN BLOG ENVIRONMENTS
}

\author{
Dr. Melih Derya GURER \\ ORCID: 0000-0002-2627-7847 \\ Faculty of Education \\ Bolu Abant Izzet Baysal University \\ Bolu, TURKEY
}

Received: 18/12/2019 Accepted: 21/02/2020

\begin{abstract}
Blogs have the potential to improve in-depth thinking, reflection, interaction and sense of community in higher education settings. Although the effectiveness of blogging on performance and thinking skills, student interaction and collaboration have been investigated by many educators, the number of studies on what influences learning in blog-based learning environments is limited. The aim of this study was to investigate the relationship between sense of community, perception of peer feedback, course engagement and learning in a blog-based learning environment. A relational study was adopted, and 170 university students participated in this study. The data of the study were collected through an online questionnaire that measures students' sense of community, peer feedback, course engagement, and perceived learning. In order to analyze the data, correlation and multiple regression tests were applied, as well as mean and standard deviation. At the end of the study, it was found that students' perceived learning, sense of community, peer feedback perceptions and course engagement were at a high level. In addition, the results of this study showed that in blog environments, students' sense of community, peer feedback perception and course engagement were significant predictors of their learning. The study findings have implications for both teachers and students and can be used as a framework to help the successful use of educational blogs.
\end{abstract}

Keywords: Blogging, sense of community, peer feedback, course engagement, perceived learning

\section{INTRODUCTION}

The emergence and development of Web 2.0 technologies have provided new environments to support collaboration and interaction. As one of these technologies, blogs, play a major role in innovative ways of meeting, sharing ideas and collaboration. Although the definition changes with the development and capabilities of technology, a blog is an acronym for "weblog" or "web-based logs". A blog can be defined as a web portal where text-based content, videos, and photos are published, and articles appear in reverse chronological order, typically run by a person or small group. Blogs have simple user interfaces and allow end-users to easily add and manage content without HTML or FTP knowledge and skills. Most blogs provide feedback from readers through the comment feature. This interactive feature describes blogs as social and network-oriented.

Among the Web 2.0 tools, blogs could be used as content creation and sharing environments to engage students, provide communication among students, teachers and public, facilitate interaction and collaboration among students and shared knowledge construction. In recent years, educational blogs have attracted the attention of both educators and researchers. Blogs have been used at primary and secondary education (Angelaina \& Jimoyiannis, 2011), higher education (Cakir, 2013; Top, 2012), professional development of teachers (Caldwell \& Heaton, 2016) and informal learning in adults (Harju, Pehkonen, \& Niemi, 2016; Holland, 2019). Previous research claims that blogs promote reflective learning because of their technical and pedagogical characteristics (Yang, 2009). In addition, blogs support the transition from superficial learning to a deeper understanding through resource and knowledge sharing, critical and reflective thinking, and teamwork and interaction (Cakir, 2013). 
In recent years, the number of studies investigating the effects of blogging on learning, student interaction, presence and perceptions of students in learning environments has increased. However, the number of studies on the factors that affect learning in blog environments is still limited. Hence, it is necessary to identify the factors that affect learning in blog-based environments (Halic, Lee, Paulus, \& Spence, 2010). Halic et al. (2010) and Top (2012) conducted studies attempting to identify these factors. However, examining the impact of different variables on learning in different blog-based learning contexts will lead to deeper and broader conclusions. The aim of this study is to examine students' perceptions of blog usage in the context of a higher education course. A better understanding of blogging in learning environments helps teachers to design and implement blog-based learning activities in different contexts and to improve the effectiveness of blogging in classroom settings. This study argues that developing a sense of community among students through blog-based discussions, peer feedback through blogs, and engagement within blog activities influence students' perceived learning levels.

\section{LITERATURE REVIEW}

\section{Blogs in Learning Environments}

In recent years, interest in blogs for learning and teaching has increased, and blogs have become one of the most popular social media tools in higher education (Angelaina \& Jimoyiannis, 2011). Blogging in education is considered to facilitate collaborative and constructivist learning through information sharing, feedback and social support (Johnson \& Johnson, 1994). According to the social constructivist learning theory, knowledge is produced by discussing society and reaching a social consensus. Because blogs provide a useful platform for reflection, they are used as an effective learning environment in the process of knowledge construction. Blogs serve as online journals and encourage students to reflect on students' experiences in blog settings (Richardson, 2005). Blogging promotes critical and analytical thinking as it enables students to interact with their peers to develop broader perspectives in the context of constructivist learning (Ellison $\&$ Wu, 2008). Jimoyiannis and Angelaina (2012) asserted that as students can construct and validate meaning through discourse, continuous reflection and content sharing, blogs enable learners to develop both social and cognitive entities as a research community. In blog-supported environments, students begin to comprehend the sharing, exchange and collaboration of knowledge that contributes to learning and professional development (Top, 2012; Wassell \& Crouch, 2008). Previous studies suggests that blogs can be used (a) as a teaching and learning tool to support active participation of students in a classroom (Kilic \& Gokdas, 2014), (b) to increase peer support and collaboration (Chang \& Chang, 2014), (c) to facilitate students' motivation and engagement in the classroom (Pursel \& Xie, 2014; Shana \& Abulibdehb, 2015); and (d) to facilitate reflection and critical thinking (Li, Bado, Smith, \& Moore, 2013; Xie, Ke, \& Sharma, 2008).

The primary purpose of blogging in higher education classrooms is to develop critical and reflective thinking and collaboration among students to promote deep learning. However, studies examining the potentials of blogs to improve learning have shown conflicting results (Chang \& Chang, 2014; Petko, Egger, \& Graber, 2014). For example, Xie et al. (2008) reported that while blogging enhanced students' reflective thinking over time, students' peer evaluation had no effect on reflective thinking. According to Chang and Chang (2014), blogging improves the contextualization of learning which is crucial for peer support, while peer feedback in online learning environments does not support students' reflective learning. In addition, students may feel more comfortable when they agreed, rather than having a different opinion with someone, fearing that they might compromise their position in the classroom. Moreover, in a quasi-experimental study, Petko, Egger, and Graber (2014) compared reflective writing on blog and paper and concluded that blogs do not provide significant benefits in terms of quality of writing.

\section{Sense of Community}

The sense of community means "the sense of belonging, the feeling that members care about each other and the group, and a common belief that the needs of the members will be met together" (McMillan \& Chavis, 1986, p. 9). In learning environments, the sense of community can be established by joint goals and responsibility, communication and interaction among students and teachers, value and interest, mutual 
respect, and behavioral and emotional engagement. It was asserted that students' sense of community is positively correlated with learning experiences, achievement, performance and learning outcomes (Sadera, Robertson, Song \& Midon, 2009). Isolation or disconnection of students from the learning community may lead to dropout and failure. Insufficient interaction and collaboration, disbelief, conflict, the presence of clues that reveal or emphasize identities and exclusion of others are reasons for isolation of the learners or disconnection of community (Rovai, 2002).

Bangert (2009) suggests that the sense of class community is an essential element of successful e-learning. Similarly, Rovai (2002, p.321) argues that "if online learners feel a sense of community, this emotional commitment can provide learners with the support they need to successfully complete a course or program and learn more". Therefore, students should be given a strong sense of community and increased emotional support should be provided. Some studies indicate that feelings of isolation and disconnection can be partially achieved, and a strong sense of community can be provided by collaboration and interaction among learners in a classroom setting (Liu, Magjuka, Bonk, \& Lee, 2007; Phirangee, 2016). Blogs can support a sense of community by increasing collaboration and interaction in face-to-face or online classes (Cuhadar $\&$ Kuzu, 2010). In addition, through blogging, students are able to share and change ideas and collaborate on learning activities to enhance a sense of community (Petersen, Chabert \& Divitini, 2006). Proper use of blogs with instructional strategies facilitates the feelings of belonging to a learning community. Through peer dialogue in a blogging environment, students can visit each other's blogs to give feedback, encourage each other, force each other to think critically, reduce their feelings of isolation, and create a community feeling (Rockinson-Szapkiw \& Walker, 2009). In the process of creating a sense of community, blogs could be used not only for grading, but also to improve students' interaction and reduce their isolation and alienation.

\section{Peer Feedback}

Peer evaluation requires the use of knowledge and thinking skills to criticize and reflect on others' work (Ballantyne, Hughes \& Mylonas, 2002). Topping (1998) asserted that reviewing, clarifying and correcting others' work involves students in new knowledge, and help students to deepen the comprehension of the new content subject. Hence, peer evaluation supports students' critical thinking and to become individual learners. In addition, it is assumed that students would be more accurate and reasonable when assessing their peers. This forces students to develop a sense of responsibility and ownership for their peer learning (Dochy, Segers \& Sluijsmans, 1999; Topping, Smith, Swanson \& Elliot, 2000). When students provide peer feedback on draft assignments through exchange of information and experience, they would have the opportunity to comprehend and reflect on their peers' assignments. This leads students to reflection and learning deep.

Social networking sites, especially blogs, offer writers the opportunity to receive formative feedback from peers and the broad public in different ways, different from traditional classroom practices. Blogs are effective when gaining deep feedback is crucial and create a learning environment that enables students to participate in effective peer feedback (Bouzidi \& Jaillet, 2009). Arslan and Aysel (2010), comparing paper-based writing instruction with writing instruction performed through blogs, showed that writing integrated with blogging could contribute to more performance than in paper-based teaching. Novakovich (2016) conducted a quasiexperimental study to test whether there were significant differences between instruction through traditional methods and through the blogging platform in terms of the quality of writing and peer feedback. The study showed that students produced higher quality writing and more critical comments in a blog environment. Yeh, Tseng, and Chen (2019) investigated the impact of online peer feedback via blogging on the speech performance of university students studying English as a Foreign Language (EFL). At the end of the study, the overall speech performance of the students increased significantly with the support of peer feedback. It was also found that students who responded more actively to peers' feedback had made more progress in the video development process.

\section{Course Engagement}

Bangert-Drowns and Pyke (2001, p.215) defined engagement as the organization of cognitive, affective and motivational strategies for explanatory procedures. The literature on student engagement indicates that active students are better learners, engage in more intensive and comprehensive learning tasks, and effective 
teaching encourages student participation (Handelsman, Briggs, Sullivan \& Towler, 2005; Bangert-Drowns $\&$ 2005). Most studies on student participation suggest that participation is a multidimensional structure that includes behavior, emotion, cognition, and social interaction (Fredricks, Blumenfeld \& Paris, 2004; Handelsman et al., 2005).

Blogging is considered as an online activity to increase students' learning, motivation and engagement. Online publishing creates a motivating learning environment for students to develop their engagement and performance in an efficient way by supporting collaboration, self-regulation and performance (Novakovich \& Long, 2013). The use of blogs in classes enables students to participate in class discussions, which increases their active participation in classroom activities (Al-Hebaishi, 2012). Kurt, Izmirli and Izmirli (2011) conducted research with 68 undergraduate students who took the Information and Communication Technologies (ICT) course in order to investigate students' perceptions about the use of blogs for complementary purposes in the courses and interviewed with them at the end of the teaching. During teaching, the students were asked to write articles on their personal blogs in order to reflect their knowledge and views on the course topics. The results of the study showed that the students involved in the blog activities showed more interest and were more successful in the course. Cameron (2012) examined whether blogs would increase student engagement in the real-world situation of the economy. As a result of the study, he stated that blogs enable students to be more interested and participatory and to be aware of current economic issues. Moreover, Kucuk and Richardson (2019) and Dixon (2015) argue that students' emotional, behavioral and cognitive engagement in online learning communities have significant effects on satisfaction and learning.

\section{Aim of the Study}

The aim of this study was to reveal the factors associated with perceived learning in a blog environment. In addition, this study examined to what extent community feeling, peer feedback, and course engagement affected students' perceived learning in a blog environment. The study sought answers to the following research questions:

- What are the students' sense of community, perception of peer feedback, course engagement and perceived learning in a blog-based learning environment?

- What is the relationship between sense of community, perception of peer feedback, course engagement and perceived learning in a blog-based learning environment?

- To what extent can students' sense of community, perception of peer feedback, course engagement predict their perceived learning in a blog-based learning environment?

\section{METHODOLOGY}

\section{Participants and the Context}

The participants of the study were 170 students at the Turkish Language Teaching Department of the Faculty of Education at a state university. Of the participants, 76 (44.7\%) of them were female and $94(55.3 \%)$ of them were male. Regarding their blogging experience, $156(91.8 \%)$ of the students had no previous blogging experience, $10(5.9 \%)$ of them had $1-3$ years of experience and $4(2.4 \%)$ of them had 5 years or more experience of blogging.

The study was carried out in the Computer II course, which is a compulsory course of students' curriculum. The students were divided into four sections. Before the implementation, the students were asked to form groups of two to four. The groups were determined based on the students' own decisions. Each group created a blog account using a service provider that provides a free blogging service. With this service provider, blog posts and web sites can be created. The researcher taught the students how to create, edit, share and publish the content with that service provider. In addition, information about how to change the interface, how to active widgets and how to use them effectively was presented.

During the spring semester, the groups created content and instructional materials using WebQuest, digital video and digital storytelling techniques, and they published their products on each group's blog pages. The instructional materials were created based on the learning achievements stated in the secondary school 
Turkish Language course program. In addition to these contents, the ADDIE model-based instructional design process which was followed to develop the instructional materials was published on the blog. Before each application, theoretical information about the instructional technique was told to the students by the researcher. The use of these techniques in the teaching of Turkish and the types of materials that could be developed with these techniques were discussed with the students. In addition, different examples were shared with them.

Each group published its detailed information and content on the product development process and its product on the blog. Regarding peer feedback, a group of students in one section evaluated both the instructional design process and the product developed by another group in another section. Semistructured and open-ended evaluation criteria for each product type and process were presented to the students. Commenting feature of the blog page were kept open so that reviewers could comment on the blog page. Based on these evaluation criteria, the students made open-ended comments on the other group's blog each week. Discussions were made on the relevant blog page while adhering to the rules of Internet ethics. Taking the feedback into consideration, the students revised both the process and the product. All these treatments lasted for 10 weeks, four hours per week. Furthermore, the peer evaluation process made up $10 \%$ of the final grade.

\section{Data Collection}

In order to collect data, Peer Feedback Perception Scale, Student Course Engagement Scale, Sense of Community Scale and Perceived Learning Scale were used. An online data collection tool was prepared to collect the data and the web address of the scale was shared with the students at the end of the semester. Students were able to answer the scales using any tool having Internet access. Since participation in the data collection part of the study was voluntary, only the volunteer students answered the scales. Six students did not participate in the data collection phase at the end of the term.

The Peer Feedback Perception Scale developed by Vaezi and Abbaspour (2015) was used to determine the students' views on peer feedback through blogs. The scale consisted of 14 items in a 5-point Likert type (1 $=$ Strongly disagree $-5=$ Strongly agree) and the reliability coefficient of the scale was computed 0.91 . The back-translation method was used to translate items into Turkish. First, a faculty member of the English Language Teaching program translated into Turkish and back-translated the questionnaire to the original language. Next, the two versions of the instrument (original language and back-translated version) are compared for concept equivalence. After exploratory factor analysis (EFA), two items were removed from the scale. The Keiser-Meier-Olkin (KMO) and Bartlett's Test of Sphericity (BTS) showed that the sample size was acceptable, and the data were appropriate $(\mathrm{KMO}=0.825, \mathrm{p}<0.05)$ for the factor analysis (Field, 2009). Twelve items were collected under three constructs - attitude toward blogging, reader role of student, and writer role of student. Three constructs explained $70.17 \%$ of the total variance which might be acceptable (Tavsancil, 2010). The internal consistency reliability coefficient of the scale was found to be high, 0.86 . In addition, the reliability coefficients of the attitude toward blogging, reader role of student, and writer role of student constructs were computed as $0.82,0.89$, and 0.86 , respectively. "I can express my thoughts comfortably with the blog", "it was unnecessary to review the assignments on the blogs of other groups", and "it helped me to hear my classmates' comments about our assignments" are examples of items in the scale.

To investigate students' engagement in the classroom, the Student Course Engagement Scale initially developed by Handelsman et al. (2005) and translated and adopted into Turkish by Author (2013) was used. It consisted of three constructs, skills, interaction and performance, and emotional. The reliability coefficient of the Turkish version of the scale was computed 0.87 . In the current study, the internal consistency reliability coefficient of scale was found to be high, 0.93 . Moreover, the reliability of the skills (0.94), interaction and performance (0.92), and emotional (0.92) constructs were high. In the scale, students were asked "To what extent do the following behaviors, thoughts, and feelings describe you, in this course. Please rate each of them on the following scale: 1 = not at all characteristic of me, $2=$ not really characteristic of me, $3=$ moderately characteristic of me, 4 = characteristic of me, 5 = very characteristic of me." "Putting forth effort", "helping fellow students", and "staying up on the readings" were sample items of this scale. 
Sense of Community and Perceived Learning Scales developed by Halic et al. (2010) were used to determine the students' perceptions of community and learning in the blog environment. The scales were adapted to Turkish by Top (2012). The Sense of Community scale consists of six items in a 5-point Likert type and examines attitudes towards blogging and community building. Some of the sample items in the scale were "The blog helps me feel connected to other students in the course" and "In comparison to my other classes, the quality of interaction with other students in this class has increased due to the blog". Top (2012) found the reliability coefficient of the scale to be 0.79 . In this study, the internal consistency coefficient of the scale was calculated as 0.75 , which was good. The Perceived Learning Scale consists of seven items in a 5-point Likert type ( 1 - Completely disagree $-5=$ Completely agree). Items such as "I believe that incorporating blogs with teaching can enhance my learning experience in general" and "the blog discussions help me to share my knowledge and experience with my peers" were on the scale. Top (2012) founded the reliability of the scale as 0.84 . In this study, it was found to be high, 0.82 . Hence, it could be said that the scales used in the current study have high reliability.

\section{Data Analysis}

Before analyzing the data, negative items in the scales were reversed. The data collected by an online questionnaire were subjected to descriptive statistics such as mean and standard deviation using SPSS 20.0 software. The normality of the data was tested on the assumption that in a normally distributed sample, $95 \%$ of the z-skewness and z-kurtosis scores should be between -1.96 and +1.96 (Field, 2009). The analysis showed that the scores from the scales had a normal distribution.

Then, bivariate and multivariate analysis were performed on the data. For example, the Pearson Correlation coefficient was calculated to examine the relationship between students' perceptions of peer feedback, course engagement, sense of community, and perceived learning. In addition, multiple regression analysis was performed to measure how well the students' perceived learning could be explained in terms of selected variables (peer feedback perception, course engagement, sense of community).

\section{FINDINGS}

\section{Descriptive Statistics}

Descriptive statistics of students' scores on the sense of community, perception of peer feedback, course engagement, and perceived learning are presented in Table 1 . The mean of the scores of the variables obtained from the five-point scale was interpreted considering the group interval for mean scores was 0.80 . While the students' sense of community $(\bar{X}=3.93)$, course engagement $(\bar{X}=3.69)$ and peer feedback perception $(\bar{X}$ $=4.16)$ were found to be moderately high, the perceived learning average was high $(\bar{X}=4.33)$.

Table 1. Descriptive statistics

\begin{tabular}{lcccc}
\hline & N & Range & $\bar{X}$ & Std. dev \\
\hline Sense of community & 170 & $1-5$ & 3.93 & .72 \\
Perception of peer feedback & 170 & $1-5$ & 4.16 & .45 \\
Course engagement & 170 & $1-5$ & 3.69 & .75 \\
Perceived learning & 170 & $1-5$ & 4.33 & .45 \\
\hline
\end{tabular}

\section{Correlations Among Variables and Regression Analysis}

Table 2 indicates the correlation coefficients among perceived learning and predictive variables. Correlation analysis indicated positive, moderate and significant correlations between perceived learning and sense of community $(\mathrm{r}=0.591, \mathrm{p}<0.01)$, peer feedback perception $(\mathrm{r}=0.697, \mathrm{p}<0.01)$, and course engagement $(\mathrm{r}$ $=0.518, \mathrm{p}<0.01)$. In addition, there was a positive and moderately significant correlation between sense of community and peer feedback perception $(r=0.612, p<0.01)$ and course engagement $(r=0.426, p$ $<0.01)$. Finally, a positive and moderately significant correlation between peer feedback perception and 
course engagement $(r=0.491, p<0.01)$ was found. The correlation coefficients among the variables were less than 0.80 , indicating that there was no multicollinearity among the variables. Therefore, it could be said that one of the assumptions of multiple regression analysis, no multicollinearity among the variables, was met (Field, 2009).

Table 2. Correlations among variables

\begin{tabular}{lrrrr}
\hline & 1 & 2 & 3 & \multicolumn{1}{c}{4} \\
\hline (1) Perceived learning & - & $.591^{* *}$ & $.697^{* *}$ & $.518^{* *}$ \\
(2) Sense of community & & - & $.612^{* *}$ & $.426^{* *}$ \\
(3) Perception of peer feedback & & & - & $.491^{* *}$ \\
(4) Course engagement & & & - \\
*** $^{*}<0,01$
\end{tabular}

Table 3 shows that the regression model was significant at $\mathrm{p}<0.001(\mathrm{~F}(3,166)=69,546, \mathrm{p}=0,00)$. With the model, $\mathrm{R}^{2}$ was found as 0.557 which means that $55.7 \%$ of the variance in perceived learning in the blog environment was significantly explained by three factors in the model (sense of community, perception of peer feedback and course engagement). As can be seen in Table 4, sense of community $(t=3.367)$, perception of peer feedback $(t=0.6736)$, and course engagement $(t=3.228)$ were significant predictors of perceived learning in blog environments. Positive weight coefficients show that they had positive effects on perceived learning. The standardized coefficients of the predictor variables were measured as peer feedback perception $(\beta=0.465)$, sense of community $(\beta=0.224)$, and course engagement $(\beta=0.195)$. In other words, a one unit increase in self-reported score of Perception of peer feedback led to 0.465 point increase in the score of perceived learning, a one point increase in the self-reported score of Sense of Community led to 0.224 point increase in the score of perceived learning, and a one unit increase in self-reported score of Course Engagement led to 0.195 point increase in the score of perceived learning. This result showed that the most influential variable on perceived learning in blog environments was the perception of peer feedback.

Table 3. ANOVA result for regression model

\begin{tabular}{lccccc}
\hline Model & Sum of squares & df & Mean square & $\mathrm{F}$ & $\mathrm{p}$ \\
\hline Regression & 19.013 & 3 & 6.338 & 69.546 & .000 \\
Residual & 15.127 & 166 & .091 & & \\
Total & 34.140 & 169 & & & \\
$\mathrm{R}=0.746$ & $\mathrm{R}^{2}=0.557$ & & $\mathrm{R}^{2}$ (adjusted) $=0.549$ & & \\
\hline
\end{tabular}

Table 4. Multiple regression model of perceived learning with sense of community, perception of peer feedback, and course engagement

\begin{tabular}{lccccc}
\hline Model & \multicolumn{2}{c}{ Unstandardized coefficients } & Standardized coefficients & $\mathrm{t}$ & $\mathrm{p}$ \\
& $\mathrm{B}$ & $\mathrm{SE} \mathrm{B}$ & $\beta$ & & \\
\hline (Constant) & 1.408 & .217 & & 6.476 & .000 \\
Sense of community & .140 & .042 & .224 & 3.367 & .001 \\
Perception of peer feedback & .466 & .069 & .465 & 6.736 & .000 \\
Course engagement & .117 & .036 & .195 & 3.228 & .002 \\
\hline
\end{tabular}




\section{DISCUSSION}

The results of the study indicate that the students' views about the use of blogs are positive and discussion through blogging contributes positively to their learning. In particular, comments made by peers on blogs are essential for students, and comments on blogs have contributed to the development of different perspectives. These results are similar to the results of the studies examining the experiences of students in blog environments. Kilic and Gokdas (2014), Kuo, Belland and Kuo (2017) and Top (2012) found that the students' perception of learning was high in blog-based learning environments and that the comments written on their blogs contributed to their learning. However, Halic et al. (2010) found a controversial result and stated that only one-quarter of the students found the feedback of the others valuable. From the social constructivist learning theory perspective, it can be said that guided, informative and high-quality comments written by peers helped the students to develop different perspectives (Johnson \& Johnson, 1994).

In blog settings, it is seen that students have a high level of feeling that they see themselves as members of a community. Students see themselves as part of a learning group during blog-based activities. Additionally, students stated that they had more interaction with peers and their interactions with peers had of higher quality in comparison to their other classes. Halic et al. (2010) and Kuo et al. (2017) also found that blogs contributed to the development of community feeling among participants who thought that sharing learning experiences and knowing others' ideas would contribute to mutual development. Similar to the results of previous studies, the results of this study indicated that sense of community was important for perceived learning (Halic et al., 2010; Kilic \& Gokdas, 2014; Kuo, et al., 2017; Top, 2012). The sense of community was found to be not only related to perceived learning but also an important determinant of it. Students' perceptions of learning in blog settings are influenced by their sense of community. According to this result, it can be predicted that the students who have a high sense of community will have a high level of learning. This result implicates that increasing students' sense of community by integrating blogs into the learning process can increase their learning experiences. Therefore, to improve the learning experiences of students at higher education level, one of the tasks of teachers would be to create a classroom community and to help students become part of this community.

Although Halic et al. (2010) claimed that students did not value feedback in blog environments, they suggest that an understanding of this result requires further studies. In this study, contrary to the study of Halic et al. (2010), it is seen that the students' opinions about using feedback in the blog environment are positive. This result is similar to the findings of Top (2012) and Kilic and Gokdas (2014). The students stated that peers' feedback helped them to identify the weaknesses in the assignments, that examining the other groups' assignments posted in their blogs contributed to their own learning and that they were able to express their thoughts easily within the blogs. Hence, it is concluded that blogs are learning environments that help to provide effective peer feedback to students. Additionally, according to the results of this study, feedback by peers on their blogs was one of the critical factors that affect their learning. It can be thought that in blog environments, the students who have more positive opinions about peer feedback will have higher perception of learning. Arslan (2014) claimed that one of the reasons that students do not believe in feedback from their peers is that they do not take peer feedback seriously. During this study, considering the evaluation criteria provided to the students by the teacher, the students made open-ended evaluations on the design process and the instructional material. Providing students with semi-structured assessment criteria rather than unstructured and providing feedback in line with these criteria may lead to better quality comments. Hence, the quality of feedback was also one of the factors affecting learning (Novakovich, 2015). Teachers can also apply semi-structured feedback activities to encourage students to reveal their reflective thinking and learn from their peers.

According to the results of the study, it can be said that students' participation in the class is high in blogbased learning environments. The students stated that they contributed to the group activities at a high level, they made great efforts to understand the subject of the course and that they had fun in the course. However, it was seen that the students did not raise their hands in the classroom or the frequency of asking questions to the teacher was low. The reason for this might be help from peers when they need or the comments on 
their blogs. Moreover, meaningful knowledge is constructed, and effective learning occurs when the level of interaction between students is high (Joo, Lim \& Kim, 2011). This result of the study is similar to the studies showing that students actively participate in class activities in blog settings (Al-Hebaishi, 2012; Kurt et al., 2011) and that blog interactions support cooperation and performance (Novakovich \& Long, 2013). It was found that students' participation in the course had a significant and positive relationship with learning and was one of the factors that significantly influence learning in blog environments. Similarly, Kucuk and Richardson (2019) and Dixon (2015) argue that one of the crucial factors that affect students' continuity and enhance learning performance is their engagement in the course. Therefore, it is expected that students who have a high level of participation in the courses will have higher learning in blog environments. Engagement, which means active participation in the course activities through continuous efforts to achieve the desired learning outcomes, affects the level of learning outcomes, cognitive development and quality of learning (Ma, Han, Yang \& Cheng, 2015). Therefore, providing students' behavioral, cognitive and emotional support or engagement and maintaining this support may contribute to higher learning.

This result suggests that students who perceive themselves as a part of a classroom community, value peer feedback, and engage in the learning activities through blogs are likely to achieve more in blog-based learning environments. Previous studies have shown that the sense of community was the most important predictor of learning in blog settings (Halic et al., 2010; Kilic \& Gokdas, 2014; Top, 2012). However, these studies were conducted without considering the perception of peer feedback and students' course engagement. When the sense of community, peer feedback perception and course engagement variables were taken together, it was found that these three variables were significant predictors of learning in blog settings and explained $55.7 \%$ of the variance in learning. This implies that the three variables have a great impact on students' learning in blog-based environments. Moreover, unlike other studies, this study revealed that peer feedback is the most significant factor among the others affecting learning in a blog setting. Therefore, this study highlighted the important relationships among the variables that influence learning in a blog environment.

\section{CONCLUSION}

Blogs have the potential to transform teaching and learning by enabling community feeling, peer feedback, and course engagement, and to enhance learning experiences. The higher the level of sense of community, peer feedback, and course engagement, the higher the perceived learning of students. This study demonstrates that students who (a) feel part of a learning community, (b) have a positive experience in their feedback through blogs, or (c) participate in teaching activities will have better learning experiences.

The most valuable feature of blogs is that it allows individual reflection, peer interaction and evaluation. This study emphasizes several points that teachers should consider when integrating blogs into learning environments. First, blogs have a higher impact when combined with compatible pedagogical environments and processes. Secondly, it is central to build a classroom community to help students learn in integrated environments, to help them develop positive experiences in peer feedback, and to engage in learning activities. The sense of community can be strengthened by the development of interaction between students. Semi-structured and open-ended peer evaluations can provide more focused and subject-specific feedback. Collaboration between students, weekly tasks and peer control of tasks can also be used to help students engage in activities.

Publishing a project or assignment on a course blog is a great convenience for a teacher in managing and supervising student assignments. The teacher has more control over the level of participation and collaboration of students. In addition, students are encouraged and motivated to achieve their work when their assignment is published online. Santos and Leahy (2014) state that writing on the web, which is a public environment, is a risky business. Unpredictable web audiences and peers are of great concern to the student. This concern leads to increased audience awareness. Therefore, it can be said that blog-based collaboration creates digital criticism on students and peer feedback helps students perform and learn better. 
This study was performed at a state university in Turkey and the cause-effect relationship has not been confirmed. Therefore, the generalizability of the results is still limited. Additional research can be conducted using different samples, courses and learning environments. The impact of blogs on students of higher education in different countries can be examined. It was found that the variables in the model explain $55.7 \%$ of the learning in the blog environment. Therefore, studies can be conducted with different variables to explain the remaining $44.3 \%$. In the study, multiple regression analysis tests were applied to predict learning in blog environments. In another study, structural equation modeling, an analysis that runs more than one multiple regression models at the same time, can be used to construct a model that measures the factors affecting learning in these settings. The present study could be further expanded by analyzing the content of the students' messages and the quality of peer feedback. Finally, the collation of quantitative data with qualitative input would help to understand the effects of the variables on learning in a more comprehensive manner.

\section{BIODATA and CONTACT ADDRESSES of AUTHOR}

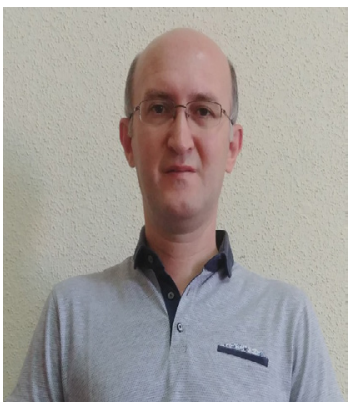

Dr. Melih Derya GURER is an assistant professor of Computer Education and Instructional Technology at the Faculty of Education in Bolu Abant Izzet Baysal University, Turkey. He holds a Ph.D. in Computer Education and Instructional Technology from Middle East Technical University, Tukey, and M.S. in Educational Administration and Supervision from Bolu Abant Izzet Baysal University, Turkey. He teaches graduate and undergraduate courses on instructional design and technology. His academic interests include online course design, technology integration in K12, and Web 2.0 technology for teaching and learning. He has various research articles published in national and international refereed journals and international book chapters.

\section{Melih Derya GURER}

Department of Computer Education and Instructional Technologies, Faculty of Education Address: Bolu Abant Izzet Baysal University, 14030, Bolu, Turkey

Phone: +90 3742541000 - 1620

E-mail: mdgurer@gmail.com 


\section{REFERENCES}

Al-Hebaishi, S. M. (2012). Pre-service teachers' perceptions towards academic blogging. Journal of Theoretical and Applied Information Technology, 37(2), 279-288.

Angelaina, S., \& Jimoyiannis, A. (2011). Educational blogging: Developing and investigating a students' community of inquiry. In A. Jimoyiannis (Ed.), Research on e-learning and ICT in education (pp. 167-180). New York, NY: Springer.

Angelaina, S., \& Jimoyiannis, A. (2012) Analysing students' engagement and learning presence in an educational blog community. Educational Media International, 49(3), 183-200. DOI:10.1080/ 09523987.2012.738012

Arslan, R. S. (2014). Integrating feedback into prospective English language teachers' writing process via blogs and portfolios. The Turkish Online Journal of Educational Technology, 13(1), 121-150.

Arslan, S., \& Aysel, S. K. (2010). How can the use of blog software facilitate the writing process of English language learners? Computer Assisted Language Learning, 23(3), 183-197. DOI: $10.1080 / 09588221.2010 .486575$

Ballantyne, R., Hughes, K., \& Mylonas, A. (2002). Developing procedures for implementing peer assessment in large classes using an action research process. Assessment \& Evaluation in Higher Education, 27(5), 427-441. DOI:10.1080/0260293022000009302

Bangert, A. W. (2009). Building a validity argument for the community of inquiry survey instrument. The Internet and Higher Education 12(2), 104-11. DOI:10.1016/j.iheduc.2009.06.001

Bangert-Drowns, R. L., \& Pyke, C. (2001). A taxonomy of student engagement with educational software: An exploration of literate thinking with electronic text. Journal of Educational Computing Research, 24(3), 213-234. https://doi.org/10.2190/0CKM-FKTR-0CPF-JLGR

Bouzidi, L., \& Jaillet, A. (2009). Can online peer assessment be trusted?. Journal of Educational Technology \& Society, 12(4), 257-268.

Cakir, H. (2013). Use of blogs in pre-service teacher education to improve student engagement. Computers \& Education, 68, 244-252. DOI:10.1016/j.compedu.2013.05.013

Caldwell, H., \& Heaton, R. (2016). The interdisciplinary use of blogs and online communities in teacher education. International Journal of Information and Learning Technology, 33(3), 142-158. DOI:10.1108/IJILT-01-2016-0006

Cameron, M. P. (2012). Economics with training wheels: Using blogs in teaching and assessing introductory economics. Journal of Economic Education, 43, 397-407. DOI:10.1080/00220 485.2012.714316

Chang, Y. J., \& Chang, Y. S. (2014). Assessing peer support and usability of blogging in hybrid learning environments. Interactive Learning Environments, 22(1), 3-17. DOI:10.1080/10494820.2011 .619889

Cuhadar, C., \& Kuzu, A. (2010). Improving interaction through blogs in a constructivist learning environment. Turkish Online Journal of Distance Education, 11(1), 134-161.

Dixon, M. D. (2015). Measuring student engagement in the online course: The online student engagement scale (OSE). Online Learning, 19(4), 1-15. DOI:10.24059/olj.v19i4.561

Dochy, F., Segers, M., \& Sluijsmans, D. (1999). The use of self-, peer and co-assessment in higher education: a review. Studies in Higher Education, 24, 331-350. DOI:10.1080/03075079912331379935

Ellison, N. B., \& Wu, Y. (2008). Blogging in the classroom: A preliminary exploration of student attitudes and impact on comprehension. Journal of Educational Multimedia and Hypermedia, 17(1), 99-122. 
Eteokleous-Grigoriou N., \& Photiou S. (2014) Integrating blogs in primary education. In: Karagiannidis C., Politis P., Karasavvidis I. (eds) Research on e-Learning and ICT in Education. Springer, New York, NY.

Field, A. (2009). Discovering statistics with SPSS, 3rd Edition. California: Sage Publications.

Fredricks, J. A., Blumenfeld, P. C., \& Paris, A. H. (2004). School engagement: Potential of the concept, state of the evidence. Review of Educational Research, 74, 59-109. DOI:10.3102/00346543074001059

Gürer, M. D. (2013). Utilization of learning objects in social studies lesson: Achievement, attitude and engagement. Unpublished Ph.D. thesis, Middle East Technical University, Turkey.

Halic, O., Lee, D., Paulus, T., \& Spence, M. (2010). To blog or not to blog: Student perceptions of blog effectiveness for learning in a college-level course. Internet and Higher Education, 13, 206-213. DOI:10.1016/j.iheduc.2010.04.001

Handelsman, M. M., Briggs, W. L., Sullivan, N., \& Towler, A. (2005). A measure of college student course engagement. The Journal of Educational Research, 98, 184-191. DOI:10.3200/JOER.98.3.184-192

Harju, V., Pehkonen, L., \& Niemi, H. (2016). Serious but fun, self-directed yet social: blogging as a form of lifelong learning. International Journal of Lifelong Education, 35(1), 2-17, DOI:10.1080/026 01370.2015 .1124930

Holland, A. A. (2019). Effective principles of informal online learning design: A theory-building metasynthesis of qualitative research. Computers \& Education, 128, 214-226. DOI:10.1016/j. compedu.2018.09.026

Johnson, D. W., \& Johnson, R. T. (1994). Professional development in cooperative learning: short-term popularity vs. long-term effectiveness. Cooperative Learning, 14, 52-54. DOI:10.1016/S0742051X(97)00039-5

Joo, Y. J., Lim, K. Y., \& Kim, E. K. (2011). Online university students' satisfaction and persistence: Examining perceived level of presence, usefulness and ease of use as predictors in a structural model. Computers \& Education, 57(2), 1654-1664. DOI:10.1016/j.compedu.2011.02.008

Kılıç, E., \& Gökdaş, I. (2014). Learning through blogging: Use of blogs to enhance the perceived learning of pre-service ICT teachers. Educational Sciences: Theory \& Practice, 14(3), 1169-1177. DOI:10.12738/estp.2014.3.1987

Kucuk, S., \& Richardson, J. E. (2019). A structural equation model of predictors of online learners' engagement and satisfaction. Online Learning Journal, 23(2), 196-216. DOI:10.24059/olj. v23i 2.1455

Kuo, Y. C., Belland, B. R., \& Kuo, Y. T. (2017). Learning through blogging: students' perspectives in collaborative blog-enhanced learning communities. Educational Technology \& Society, 20(2), $37-50$.

Kurt, A. A., Izmirli, S. \& Sahin-Izmirli, O. (2011). Student experience in blog use for supplementary purposes in courses. Turkish Online Journal of Distance Education, 12(3), 78-96.

Li, K., Bado, N., Smith, J., \& Moore, D. (2013). Blogging for teaching and learning: An Examination of experience, attitudes, and levels of thinking. Contemporary Educational Technology, 4(3), 172186.

Liu, X., Magjuka, R. J., Bonk, C. J., \& Lee, S. (2007). Does sense of community matter? Quarterly Review of Distance Education, 8, 9-24.

Ma, J., Han, X., Yang, J., \& Cheng, J. (2015). Examining the necessary condition for engagement in an online learning environment based on learning analytics approach: The role of the instructor. Internet and Higher Education, 24, 26-34. DOI:10.1016/j.iheduc.2014.09.005 
McMillan, D. W., \& Chavis, D. M. (1986). Sense of community: A definition and theory. Journal of Community Psychology, 14, 6-23. DOI:10.1002/1520-6629(198601)14:1<6::AIDJCOP2290140103>3.0.CO;2-I

Novakovich, J. (2016). Fostering critical thinking and reflection through blog-mediated peer feedback. Journal of Computer Assisted Learning, 32, 16-30. DOI:10.1111/jcal.12114

Novakovich, J., \& Long, E. (2013). Digital performance learning: Utilizing a course weblog for mediating communication. Journal of Education Technology and Society, 16(4), 231-241.

Petersen, S. A., Chabert, G., \& Divitini, M. (2006). Language learning: Design considerations for mobile community blogs. IADIS International Conference Mobile Learning (pp. 14-15). Dublin.

Petko, D., Egger, N., \& Graber, M. (2014). Supporting learning with weblogs in science education: A comparison of blogging and hand-written reflective writing with and without prompts. Themes in Science \& Technology Education, 7(1), 3-17.

Phirangee, K. (2016). Students' perceptions of learner-learner interactions that weaken a sense of community in an online learning environment. Online Learning, 20(4), 13-33.

Pursel, B. K., \& Xie, H. (2014). Patterns and pedagogy: Exploring student blog use in higher education. Contemporary Educational Technology, 5(2), 96-109.

Richardson, W. (2005). Blogs, wikis, podcasts, and other powerful web tools for classrooms. Thousand Oaks, CA: Corwin Press.

Rockinson-Szapkiw, A. J., \& Walker, V. L. (2009). Web 2.0 technologies: Facilitating interaction in an online human services counseling skills course. Journal of Technology in Human Services, 27(3), 175-193. DOI:10.1080/15228830903093031

Rovai, A. P. (2002). Sense of community, perceived cognitive learning, and persistence in asynchronous learning networks. The Internet and Higher Education, 5(4), 319-332. DOI:10.1016/S10967516(02)00130-6

Sadera, W. A., Robertson, J., Song, L., \& Midon, M. N. (2009). The role of community in online learning success. MERLOT Journal of Online Learning and Teaching, 5, 277-284.

Sánchez, B., Colón, Y., \& Esparza, P. (2005). The role of sense of school belonging and gender in the academic adjustment of Latino adolescents. Journal of Youth and Adolescence, 34, 619-628. DOI:10.1007/s10964-005-8950-4.

Santos, M. C., \& Leahy, M. (2014). Postpedagogy and web writing. Computers and Composition, 32, 84-95. DOI:10.1016/j.compcom.2014.04.006

Shana, Z. A., \& Abulibdehb, E. S. (2015). Engaging students through blogs: Using blogs to boost a course experience. International Journal of Emerging Technologies in Learning, 10(1), 30-38. DOI:10.3991/ijet.v10i1.4240

Tavşancıl, E. (2010). Tutumların ölçülmesi ve SPSS ile veri analizi. Ankara: Nobel Yayın Dağıtım.

Top, E. (2012). Blogging as a social medium in undergraduate courses: Sense of community best predictor of perceived learning. The Internet and Higher Education, 15, 24-28. DOI:10.1016/j. iheduc.2011.02.001

Topping, K. (1998). Peer assessment between students in colleges and universities. Review of Educational Research, 68, 249-276. DOI:10.3102/00346543068003249

Topping, K., Smith, F. F., Swanson, I., \& Elliot, A. (2000). Formative peer assessment of academic writing between postgraduate students. Assessment and Evaluation in Higher Education, 25, 149-169. DOI: $10.1080 / 713611428$

Tse, S.K., Yuen, A.H.K., Loh, E.K.Y., Lam, J.W.I., \& Ng, R.H.W. (2010). The impact of blogging on Hong Kong primary school students' bilingual reading literacy. Australasian Journal of Educational Technology, 26(2), 164-179. DOI:10.14742/ajet.1088 
Vaezi, S., \& Abbaspour, E. (2015). Asynchronous online peer written corrective feedback: effects and affects. In: Mehrak R. (Ed.), Handbook of Research on Individual Differences in Computer-Assisted Language Learning, (pp 271-297). PA: USA.

Wassell, B., \& Crouch, C. (2008). Fostering critical engagement in preservice teachers: Incorporating weblogs into multicultural education. Journal of Technology and Teacher Education, 16(2), 211-232.

Xie, Y., Ke, F., \& Sharma, P. (2008). The effect of peer feedback for blogging on college students' reflective learning processes. The Internet and Higher Education, 11(1), 18-25. DOI:10.1016/j. iheduc.2007.11.001

Yang, S. H. (2009). Using blogs to enhance critical reflection and community of practice. Educational Technology \& Society, 12(2), 11-21.

Yeh, H. C., Tseng, S.-S., \& Chen, Y.-S. (2019). Using online peer feedback through blogs to promote speaking performance. Educational Technology \& Society, 22(1), 1-14. 